\title{
Envenomation by the hump nosed viper (hypnale hypnale) in children: a pilot study
}

\author{
D H Karunatilaka ${ }^{1}$, G W D S Herath ${ }^{2}$, H H S Lalani², K D N I Perera ${ }^{2}$
}

Sri Lankan Journal of Child Health, 2001; 30: 8-11

(Key words: hump nosed viper, hypnale hypnale, envenomation, children)

\begin{abstract}
Aim of study To study the epidemiological pattern and the effects of envenomation by the hump nosed viper () in children. All previous publications on this subject are based on the adult experience.
\end{abstract}

Location Health Department Paediatric Unit, Colombo South Teaching Hospital.

Method Prospective descriptive study.

Conclusion There are significant epidemiological differences between the bites observed in children as opposed to adults. The effects of local envenomation were seen in all child victims, but only five showed evidence of systemic envenomation. The effects of systemic envenomation appear to be related to the body surface area and are commoner than in adult patients. The effects of systemic envenomation manifest very early in the case of children.

\section{Introduction}

Venomous snakebites are common in Sri Lanka. An annual incidence of 61,000 bites and a mortality rate of 5.7 per 100,000 population was reported in $1979^{1}$, but a marked decline in mortality has been observed in recent years $^{2}$. The majority of venomous snakebites in Sri Lanka are due to the merium hump nosed viper (hypnale hypnale), which has the widest distribution in the island from the coast to the hill country and in the dry zone ${ }^{1}$.

The incidence of hump nosed viper bites in the Colombo District and in the catchments areas of the Teaching Hospital Colombo South in particular, appears to be on the increase ${ }^{2}$. This is probably due to rapid urbanization programmes and the clearing of shrub jungles in the suburbs by real estate investors for housing projects, thus driving the snakes out of their natural habitat. Severe renal toxicity due to hypnale bites were initially documented by Varagunam and Panabokke $^{3}$ in 1970 followed by Rezvi Sheriff ${ }^{4}$ in 1983. However, several cases of serious envenomation with diverse toxic manifestations due to hypnale bites have been reported in recent literature ${ }^{5,6,7,8,9}$. All studies

\footnotetext{
${ }^{1}$ Consultant Paediatrician, ${ }^{2}$ Paediatric Registrar, Colombo South Teaching Hospital
}

carried out so far in Sri Lanka have been based on adult patients. We conducted a prospective study to evaluate the effects of hypnale bites on children, and to see how these experiences differ from the previously reported studies in adults.

\section{Material and methods}

The study was conducted from July 1997 to December 1998 at the Colombo South Teaching Hospital. Fourteen previously healthy children who were admitted to the Health Department's Paediatric Unit, after being bitten by hump nosed viper were studied. Informed consent was obtained from the parents and the study was approved by the hospital administration. The snake was identified by the principal investigator [DHK] by visual examination of snakes in 8 cases and by the parents who were conversant with identification in 6 cases. Their capacity to do so was verified by showing formalin preserved specimens. A detailed history was obtained from the parents in each case with the active participation of the victims wherever possible. The time of bite, a prolonged oozing from the site, times and volume of urine passed since, and treatment received, if any, prior to admission were all recorded.

In addition to the routine examination, each child was specially examined for features of local envenomation and the local effects were graded from 1-6 as shown in Table 1 .

Table 1

Grades of local envenomation

\begin{tabular}{|l|l|}
\hline Grade 1 & redness and mild swelling \\
\hline Grade 2 & redness and extensive swelling \\
\hline Grade 3 & Grade $2+$ blistering \\
\hline Grade 4 & Grade $3+$ severe pain \\
\hline Grade 5 & Grade $4+$ necrosis \\
\hline Grade 6 & Grade $5+$ regional lymphadenopathy \\
\hline
\end{tabular}

All patients were carefully observed for a period of 4872 hours for evidence of any features suggestive of systemic envenomation such as ptosis, opthalmoplegia, drop in urine output, prolonged oozing from the site, drowsiness and weakness of muscles. The bleeding time, clotting time, platelet count, serum potassium, blood urea, and urine full report were carried out in all patients within the first 12 hours and subsequently more often where necessary. 
All but three patients were given tetanus toxoid and those showing local effects of grade 3 and above, received antibiotics. All those who did not have evidence of systemic envenomation were discharged from hospital after 48 hours with appropriate advice regarding the management of soft tissue injuries. They were briefed about the possibility of developing delayed renal failure and were advised to report back immediately, should they develop oliguria. The mean duration of stay in hospital was 3-6 days.

\section{Results}

Thirteen patients out of a total of fourteen completed the study and one left against medical advice a few hours after admission. The mean time lapse from the bite to the arrival at the hospital was 2.03 hours (Table 2).

Table 2

Descriptive statistics showing the time lapse from the bite to the arrival at hospital

\begin{tabular}{|c|c|c|c|c|}
\hline & $N$ & Mean & Mean & Std. \\
\hline & Statistic & Statistic & Std. Error & Statistic \\
\hline TIME & 13 & 2.0325 & .3642 & \\
$\begin{array}{c}\text { Valid N } \\
\text { (listwise) }\end{array}$ & 13 & & & \\
\hline
\end{tabular}

Epidemiology of hump nosed viper bites is shown in Table 3.

Table 3

Epidemiology of hump nosed viper bites

\begin{tabular}{|c|c|c|c|c|}
\hline Case No. & Age (yrs) & Time lapse (hrs) & Time of bites & Site of Bite \\
\hline 1 & 6 & 3 & 4.50 PM & hand \\
2 & 10 & 0.25 & 6.00 PM & Foot \\
3 & 11 & 1.33 & 6.15 PM & Foot \\
4 & 0.5 & 1 & 7.30 PM & Foot \\
5 & 3.5 & 4 & 5.45 PM & Hand \\
6 & 12 & 2 & 8.30 PM & Foot \\
7 & 6 & 4 & 4.30 PM & Foot \\
8 & 4 & 3.5 & 7.30 PM & Calf \\
9 & 7 & 1 & 2.30 PM & Hand \\
10 & 1.75 & 3 & 11.00 PM & Calf \\
11 & 1.5 & 0.5 & 9.00 PM & Thigh \\
12 & 9 & 1.5 & $12.30 \mathrm{PM}$ & Foot \\
\hline
\end{tabular}

Analysis of epidemiological data is shown in Table 4.

Table 4

Analysis of epidemiological data

\begin{tabular}{l|l} 
The median age of victims & 6.00 Years \\
The mean age of victims & 5.84 Years \\
The mean time lapse before arrival at hospital & 2.03 hours \\
Time of Bite & 7.00 AM - 12 Noon $n=1(7.6 \%)$ \\
& 12 Noon -5.00 PM $n=5(38.45 \%)$ \\
& 5.00 PM -10 PM $n=7(53.84 \%)$ \\
Provoked & $n=10(76.92 \%)$ \\
Unprovoked & $n=3(23.07 \%)$ \\
Site of Bite & Foot $n=7(53.8 \%)$, Calf $n=2(15.38 \%)$, \\
& Hand $n=3(23 \%)$ Thigh $n=1[7.6 \%]$
\end{tabular}

Out of the thirteen patients studied, a six month old baby, who also happened to be the youngest patient in the study, developed acute renal failure two and a half hours after the bite and was peritoneally dialysed 
48 hours later. Dialysis was carried out in the ward for a period of seven days before he recovered. This is the youngest patient to have been dialysed in this country for a snake bite. He still remains well without any untoward sequelae. This same patient developed disseminated intravascular coagulation with mucosal and cutaneous bleeding. His bleeding and clotting times were markedly raised and the platelet count was low. There was another patient with prolonged oozing from the site of bite with normal bleeding time and temporary disturbance of renal function. He was unusually drowsy for twenty four hours showing evidence of mild encephalopathy.

Three other patients had prolonged oozing and increased clotting times without any evidence of raised bleeding times or renal involvement.

\section{Discussion}

This study shows that unlike in the case of adult victims, in whom the bites are almost confined to the hands and feet, a few of our patients were bitten on the calf and thigh. All our victims were bitten between $11 \mathrm{AM}$ and $6 \mathrm{PM}$, in contrast to the published data in adults where bites occurred mainly between $6 \mathrm{PM}$ and $11 \mathrm{PM}$. This is probably due to the disturbance caused to these snakes during daytime by children. Almost all patients showed evidence of local envenomation but only $30.7 \%$ of the patients showed skin necrosis with or without regional lymphadenopathy. This study also shows that the effects of local envenomation are far more severe in children than those reported in adults. One patient in our study developed acute renal failure while another showed evidence of temporary disturbance in renal function and prolonged oozing with normal BT and CT. Four patients showed evidence of coagulapathy with an increase in clotting time and prolonged oozing. Prolonged oozing in these patients was due to excessive fibrinolysis ${ }^{5}$. This brings the total number of patients showing features of systemic envenomation in our study to five $(38.5 \%)$, which is significantly higher when compared with the published data for adults.

The other point of interest is that there seems to be an inverse relationship between the body surface area and the degree of systemic envenomation, those with a smaller surface area showing far more serious systemic manifestations than those with relatively a higher body SA (Table 5). Furthermore, the surface area of the child shows a significant negative correlation with the local effects $(\mathrm{r}=0.846, \mathrm{P}<0.01)$ (Table 6).

Table 5

Relationship of systemic and local envenomation to SA (SA in an ascending order) $\mathbf{n = 1 3}$

\begin{tabular}{|c|c|c|c|c|c|c|c|}
\hline $\begin{array}{l}S A \\
\left(m^{2}\right)\end{array}$ & $\begin{array}{c}\text { Grade of BT } \\
\text { Local env. }\end{array}$ & $\begin{array}{c}\text { Raised Bl. } \\
\text { Urea }\end{array}$ & $\begin{array}{c}\text { Decreased } \\
\text { UOP }\end{array}$ & $\begin{array}{c}\text { Prolonged } \\
\text { oozing }\end{array}$ & $\begin{array}{l}\operatorname{Inc} \\
\quad C T\end{array}$ & $\begin{array}{c}\text { Decreased } \\
\text { platelets }\end{array}$ & $\begin{array}{l}\text { Neuro. } \\
\text { effects }\end{array}$ \\
\hline 0.32 & 5 & + & + & + & + & + & + \\
\hline 0.44 & 6 & & & + & + & & \\
\hline 0.46 & 6 & & & + & + & & \\
\hline 0.57 & 4 & & & & & & \\
\hline 0.62 & 5 & + & + & + & & & + \\
\hline 0.69 & 4 & & & + & + & & \\
\hline 0.76 & 2 & & & & & & \\
\hline 0.80 & 3 & & & & & & \\
\hline 0.86 & 3 & & & & & & \\
\hline 0.88 & 2 & & & & & & \\
\hline 0.89 & 3 & & & & & & \\
\hline 0.92 & 3 & & & & & & \\
\hline 1.08 & 1 & & & & & & \\
\hline
\end{tabular}


Table 6

Nonparametric correlation showing the relationship of SA to the local effects

\begin{tabular}{|lccc|}
\hline \multirow{2}{*}{ Sperman's rho S. Area } & S. Area & L. effects \\
& Correlation & 1.000 & -.846 \\
& Coefficient & & 13 \\
L. effects & $\mathrm{N}$ & 13 & 1.000 \\
& $\cdot$ & -.846 & 13 \\
& Correlation & 13 & \\
& Coefficient & & \\
& & &
\end{tabular}

We conclude that the hump nosed viper bites in children show a higher incidence of both local and systemic effects and the effects are more pronounced in younger children below the age of three years. There are also significant epidemiological differences between the bites in children when compared to those of to adults.

\section{Acknowledegments}

We acknowledge the assistance given in statistical analysis by Prof. Kumudu Wijewardena, Head of the Community Medicine Department, Sri Jayawardenepura University and the house officers and the nursing staff of ward 15A of the Colombo South Teaching Hospital, who helped us in this study.

\section{References}

1. De Silva A, Ranasinghe L. Epidemiology of snake bite in Sri Lanka. Ceylon Medical Journal 1983; 28: $144-54$

2. Ministry of Health Sri Lanka, Annual Health Bulletin 1998.

3. Waragunam T, Panabokke R G. Bilateral cortical necrosis of the kidneys following snake bite. Postgraduate Medical Journal 1970 46: 449.

4. Sheriff M H Rezvi. Renal diseases due to snake bite and its management. Ceylon Medical Journal 1983; 28: 190 -8.

5. Premawardena A P, Senevirathna S L, Gunatilaka S B, De Silva H J. Excessive Fibrinolysis: the coagulopathy following Merium hump-nosed viper (hypnale hypnale) bites. American Journal of Tropical Medicine 1998; 58(6): 821 -8.
6. Dharmaratne, Gunawardena U. Generalized bleeding tendency and acute renal failure following hump-nosed viper bites. Journal of the Ceylon College of Physicians 1988-89; 2122: $37-42$.

7. Kularathna S A M, Ranatunga N. Severe systemic effect of merium hump-nosed viper bites. Ceylon Medical Journal 1999; 44:169-70.

8. Sellahewa $\mathrm{K} \quad \mathrm{H}$, Kumararatne $\mathrm{M} \quad \mathrm{P}$. Envenomation by the hump-nosed viper (hypnale hypnale) American Journal of Tropical Medicine 1994; 5 (6): 822-5.

9. Sellahewa K H. Lesson from four slides on the management of snake bites in Sri Lanka. Ceylon Medical Journal 1997; 42: 8 -15.

10. Sellahewa K H, Gunawardena G, Kumaratne M P. Efficacy of antivenom in the treatment of severe local envenomation by the hump-nosed viper. American Journal of Tropical Medicine 1995; 53 (3): 260-2.

11. Sellahewa K H, Kumaratne M P, Dassanayake P B. Intravenous immunoglobulin in the treatment of snake bite envenomation. Ceylon Medical Journal 1994; 39: 173-5. 
